\title{
(DES)HUMANIZAÇÃO E SOCIEDADE CAPITALISTA: PARADOXOS DE TRABALHO, ARTE E EDUCAÇÃO
}

\author{
Carla Irene Roggenkamp ${ }^{1}$ \\ Maria José Dozza Subtil ${ }^{2}$
}

\section{RESUMO}

O presente artigo tem por objeto o homem humanizado e o desenvolvimento de sua sociabilidade através do trabalho criativo e da expressão artística mediados pela educação. Estes elementos se encontram, na sociedade capitalista, estabelecida sobre um sistema baseado na divisão hierárquica do trabalho, em contradição. O trabalho criativo, a arte original e a educação libertadora se encontram entrelaçadas com aspectos alienantes, estandardizados e opressores, frequentemente desumanizadores. A sociedade de classes, regida pela lógica do mercado, apresenta-se como hostil à criação, seja ela no contexto do trabalho ou no da arte. Dão suporte à esta discussão autores fundamentados no Materialismo Histórico e Dialético como Ostrower (1987), Vásquez (1987) e Fischer (2002), além de trabalho de Marx (2006, 2008) e Mészáros (2002).

Palavras-chave: Trabalho; Arte; Educação; Capitalismo

\section{(DE)HUMANIZATION AND CAPITALIST SOCIETY: LABOR, ARTAND EDUCATION PARADOXES}

\begin{abstract}
This is an article about the humanized man and the development of his sociability through creative work and artistic expression mediated by education. These elements can be found in contradiction in the capitalist society, established upon a hierarchical division of labor. Creative Labor, original art and liberating education frequently find themselves interlaced with dehumanizing, oppressive, alienating, standardized aspects. The class society, governed according to the market's logic, presents itself as hostile to creative labor and art. Support this discussion authors based on Historical and Dialectical Materialism such as Ostrower (1987), Vásquez (1987) and Fischer (2002), in addition to Marx (2006, 2008) and Mészáros (2002).
\end{abstract}

Key words: Labor; Art; Education; Capitalism

\section{Introdução}

"O homem elabora seu potencial criador através do trabalho. É uma experiência vital. Nela o homem encontra sua humanidade" (OSTROWER, 1987, p.31). O trabalho criativo e, por extensão, a arte, são, segundo Ostrower (1987), elementos fundamentais para a humanização do ser humano. O trabalho e a arte, mediados e socializados pela educação, serão apresentados, no entanto, ao longo deste trabalho, em uma relação conflitante com o sistema de reprodução social estabelecido, a saber, o capitalismo, pois, mesmo sendo elementos fundantes da humanização do homem e de sua elaboração enquanto ser social, no sistema capitalista de produção estes mesmos elementos - trabalho alienado, arte estandardizada e educação opressora - se transformam em elementos de manutenção a serviço do sistema. 
O homem, através do trabalho, desenvolveu suas diversas formas históricas de sociabilidade ao transformar a natureza e, nesse processo transformar-se a si mesmo. É esse ser, capaz de transformar a natureza de tal forma a não mais ser escravizado pelas necessidades biológicas básicas, mas repleto de necessidades humanas e sociais, que é compreendido como humano. Assim, muito mais do que um conjunto de aspectos psicológicos e biológicos, o ser humano pleno é aquele que se ergue ante a natureza e, ao invés de se adaptar a ela, adapta-a aos seus interesses, ao produzir, a partir do que lhe é oferecido naturalmente, um mundo humanizado.

Segundo Marx (2008), "o modo de produção da vida material condiciona o processo de vida social, política e intelectual. Não é a consciência dos homens que determina o seu ser; ao contrário, é o seu ser social que determina sua consciência" (MARX, 2008, p.47). Desta forma, o processo de construção do ser humano inicia-se, nos grupos humanos primitivos, a partir do momento que o homem, ao desenvolver técnicas baseadas em instrumentos por ele fabricados, passou a ter condições de suprir as suas necessidades de subsistência. Quando, com o uso de ferramentas cada vez mais aprimoradas, o homem passou a ter suas necessidades físicas, e as de seu grupo social, atendidas com maior facilidade, podendo desfrutar de períodos de tranquilidade e ócio, desenvolvem-se as necessidades verdadeiramente humanas, ou ainda espirituais, no grupo das quais se situam as relações sociais, a religiosidade, o divertimento e a fruição estética.

Para Marx (2006), o ser humano se distingue dos animais pela possibilidade de pensar, de distanciar-se do mundo e refletir sobre ele. Esse refinamento dos sentidos, que se expressa pela fruição estética, que só é possível ao homem, depende, antes de tudo, de que as necessidades básicas de sobrevivência sejam supridas, pois, um homem que morre de fome dificilmente vai encontrar prazer num objeto artístico (MARX, 2006, p. 144).

O reconhecimento do belo, a sensibilidade estética, só é possível na medida em que o ser humano se afirma face à natureza adversa, não existindo o belo em si, mas apenas em sua relação com o homem. Esta centralidade humana é essencial para a compreensão da fruição estética, pois "todos os acontecimentos, tudo o que nos possa afetar e o que possamos querer saber, têm em comum o homem e a cultura humana. Estão ligados a partir do homem, através do homem, em relação ao homem" (OSTROWER, 1987, p.38). O belo é, portanto, o que o ser humano, tendo supridas suas necessidades básicas, elabora e compreende como tal.

Dessa forma, enquanto o trabalho supre necessidades utilitárias de subsistência, a arte supre necessidades espirituais. O homem somente produz verdadeiramente "quando se acha livre da necessidade física", podendo "[...] produzir objetos que satisfazem necessidades materiais cada vez mais distantes até chegar a criar objetos que satisfazem, primariamente, uma necessidade humana meramente espiritual" (VÁZQUEZ, 1978, p.72).

A arte origina-se da superação do meramente utilitário no trabalho humano, quando as sociedades primitivas deram início ao uso de elementos decorativos em seus utensílios, e na figuração (imagens de animais, principalmente) da pintura rupestre. Assim, a concepção de que o trabalho e a arte são atividades antagônicas, pode ser superada, pois a arte, em essência, amplia e enriquece o mundo humano conquistado pelo trabalho.

A capacidade de humanizar os objetos e, além disso, de superar os marcos do trabalho compreendido em sua função utilitária, ou seja, suprindo necessidades biológicas básicas, é o que impulsiona a criação artística. A "utilidade" da arte situa-se, portanto, no campo do espiritual, na medida em que "satisfaz a necessidade do homem de humanizar o mundo que lhe rodeia e de enriquecer com o objeto criado sua capacidade de comunicação" (VÁZQUEZ, 1978, p.204). 
Comentando os Manuscritos econômicos e filosóficos, de 1844, Vázquez (1978) afirma que, para Marx, a arte não é

uma atividade humana acidental, mas um trabalho superior no qual o homem explicita suas forças essenciais como ser humano e as objetiva ou materializa num objeto concreto-sensível. O homem é homem na medida em que cria um mundo humano, e a arte aparece como uma das mais elevadas expressões deste processo de humanização (VÁZQUEZ, 1978, p.110-111).

A educação participa deste processo humanizador na medida em que se faz necessário que trabalho e arte, em seus objetos e técnicas de produção, uma fez formulados criativamente, sejam disponibilizados para o usufruto de todo um conjunto social.

\section{Divisão social e hierárquica do trabalho}

Diante do aumento gradativo das necessidades humanas - necessidades estas supridas pelo trabalho tanto nos limites do utilitário (ferramentas) quanto em seus aspectos espirituais (religião, arte, expressão), e socializados pela educação (em seus diferentes estágios, desde a relação informal no âmbito da família, passando pela relação intermediária entre mestre e aprendiz, até a institucionalização do aprendizado) - de grupos sociais cada vez mais numerosos e complexos, a divisão do trabalho entre os diversos indivíduos pertencentes à sociedade tornou-se um imperativo. Essa divisão de trabalho, no entanto, não se estabelece como hierárquica de imediato.

Mészáros (2002) denomina de "totalidade agregativa" esta peculiaridade humana caracterizada pelo convício sócio comunitário, e, em relação a ela, afirma:

A especificidade histórica de uma forma de mediação dada, através da qual os indivíduos se reúnem em um todo social mais ou menos entrelaçado, por meio de agrupamentos historicamente dados e respectivos corolários institucionais, tem importância seminal. É precisamente esta especificidade mediadora das inter-relações reprodutivas dos indivíduos - praticamente inevitável - que define, em última análise, o caráter fundamental dos diversos modos de intercâmbio historicamente contrastantes (MÉSZÁROS, 2002, p.67).

Com a divisão do trabalho, despontam as especialidades, as profissões, a possibilidade de que diferentes indivíduos contribuam para a sua comunidade de modo distinto, para suprir uma ou algumas das necessidades desta comunidade, e simultaneamente, tendo suas próprias necessidades ampliadas contempladas mediante o trabalho de seus pares, através de mecanismos de troca ou, mais tarde, do mercado (MARX, 1982, p. 64-65).

A divisão do trabalho não é, no entanto, algo ontológico e inalterável, característico à condição humana, mas, resultado da complexificação social, sendo, portanto, uma determinação histórica. Na divisão do trabalho, pensada historicamente, os indivíduos "são mediados entre si e combinados em um todo social antagonicamente estruturado por meio do sistema estabelecido de produção e troca” (MÉSZÁROS, 2002, p.67).

O mundo humano é, por excelência, um mundo social, e o intercâmbio entre os homens se dá na medida em que cada indivíduo, para alcançar seu pleno desenvolvimento, possa "se apoderar das experiências alheias que potencialmente lhe concernem, que 
poderiam ser dele. E o que um homem sente como potencialmente seu inclui tudo aquilo de que a humanidade, como um todo, é capaz" (FISCHER, 2002, p.13). A educação para a arte é um meio privilegiado capaz de suprir essa necessidade de união com o todo ao refletir a "infinita capacidade humana para a associação, para a circulação de experiências e ideias" (FISCHER, 2002, p.13).

A alienação do trabalhador ocorre, no entanto, na sociedade industrializada, na medida em que o desenvolvimento fabril, e o uso de máquinas para funções cada vez mais específicas, acentua a divisão do trabalho, agora hierarquizada, transferindo ao operário apenas a "operação mais simples, mais monótona, mas fácil de aprender. Desse modo, o custo do operário se reduz, quase exclusivamente, aos meios de manutenção que the são necessários para viver e perpetuar sua existência" (MARX; ENGELS, 1999, p. 18), uma vez que não se faz necessária nenhum tipo de educação ou formação abrangente, bastando a instrução técnica ferramental - sendo que a educação, neste contexto, se estabelece como uma ferramenta de mera reprodução social visando a manutenção do trabalhador "no seu lugar" -, ao mesmo tempo em que se aprofunda o abismo entre a arte e a maior parte da população.

\section{Arte, trabalho e sistema capitalista de produção}

Fischer (2002) aponta para o fato de que, na sociedade capitalista, artistas e escritores significativos não tem encontrado maneiras de se pôr de acordo com a realidade social. No sistema capitalista "toda arte situada acima de certo nível de mediocridade tem sido uma arte de protesto, crítica e revolta" (FISCHER, 2002, p.118), não encontrando, na maioria dos casos, grande repercussão entre as classes trabalhadoras.

O sistema de produção capitalista, remontando à sua origem, ao promover a crescente alienação do trabalhador frente ao seu trabalho, transforma os trabalhadores em apenas mais uma peça de maquinário, capazes de, através do trabalho padronizado e controlado, favorecer o acúmulo de riqueza (capital) das classes detentoras dos meios de produção. Estes indivíduos, produtores de mercadorias, são também, eles mesmos, obrigados a vender diariamente a sua força de trabalho de modo a garantir suas condições mínimas de subsistência, tornando-se "artigo de comércio como qualquer outro" (MARX; ENGELS, 1999, p. 18), ou seja, submetendo a sua sobrevivência às leis do mercado.

Vázquez (1978) observa que o mesmo ocorre com a arte banalizada, produzida industrialmente para o entretenimento das classes trabalhadoras. $\mathrm{O}$ trabalho, que deveria se assemelhar à arte, ou seja, mostrar-se livre e criador, na sociedade capitalista, torna-se alienante, e a arte, nesse mesmo contexto, vem sendo subjugada à lógica do trabalho fabril (VÁZQUEZ, 1978, p.112).

Ostrower (1987) critica este modelo de padronização no trabalho ao insistir na humanização vinculada ao trabalho livre e criativo. Segundo a autora,

O vício de considerar que a criatividade só existe nas artes, deforma toda a realidade humana. Constitui uma maneira de encobrir a precariedade das condições criativas em outras áreas de atuação humana [...]. Constitui, certamente, uma maneira de se desumanizar o trabalho. Reduz o fazer a uma rotina mecânica, sem convicção ou visão ulterior de humanidade. Reduz a própria inteligência humana a um arsenal de informações 'pertinentes', não relacionáveis entre si e desvinculadas dos problemas prementes da humanidade (OSTROWER, 1987, p.39). 
O trabalho livre é criação, e a arte é a criação por excelência. O trabalho livre deveria aproximar-se, portanto, da arte ao permitir ao homem que, mesmo ao suprir necessidades materiais utilitárias, ele se reconheça no produto de seu trabalho e na construção de uma sociedade humana.

O discurso hegemônico, no entanto, afirma o "caráter universalmente benéfico do [...] capital permanente universal. [...] A harmoniosa conciliação de todos os seus constituintes antagonistas para benefício de todos" (MÉSZÁROS, 2002, p. 68), escamoteando a verdadeira realidade da exploração, pautada sobre as "desigualdades naturais" entre os homens.

Segundo Mészáros (2002), o capital exerce controle sobre todas as relações sociais e humanas na sociedade contemporânea.

Não se pode imaginar um sistema de controle mais inexoravelmente absorvente - e, neste importante sentido, 'totalitário' - do que o sistema do capital globalmente dominante, que sujeita cegamente aos mesmos imperativos a questão da saúde e a do comércio, a educação e a agricultura, a arte e a indústria manufatureira, que implacavelmente sobrepõe a tudo seus próprios critérios de viabilidade, desde as menores unidades de seu 'microcosmo' até as mais gigantescas empresas transnacionais, desde as mais íntimas relações pessoais aos mais complexos processos de tomada de decisão dos vastos monopólios industriais, sempre a favor dos fortes e contra os fracos (MÉSZÁROS, 2002, p.96).

Com o advento do sistema de produção capitalista, fundado sobre a apropriação da "força de trabalho excedente", ou seja, a mais-valia ${ }^{3}$, a acumulação do capital passa a gerir os interesses das classes dominantes, proprietárias dos meios de produção, em detrimento da satisfação das necessidades sociais e de subsistência dos trabalhadores, proprietária unicamente de sua própria força de trabalho. Como resultado desse processo aparece a banalização da vida humana, que caracteriza a sociedade capitalista.

$\mathrm{O}$ trabalho alienado ${ }^{4}$ não permite ao homem a conexão com o produto de seus esforços. Na produção capitalista, o produto importa menos pelas suas características de suprir uma determinada necessidade humana do que pelo seu valor de troca, uma vez que, para o capitalista, "o luxo pode significar satisfação para os seus desejos privados, mas implica também ostentação de riqueza como meio de obter crédito e prestígio" (FISCHER, 2002, p.61). O sistema capitalista não é propício à educação humanizadora e, por consequência, à arte e à promoção desta, na medida em que é contrário à libertação do homem das correntes que o prendem ao trabalho banalizado, sendo que a arte industrializada se presta para fins de "embelezamento de sua vida privada ou apenas como um bom investimento" (FISCHER, 2002, p.61).

Marx (2006) questiona esse sentido de posse que constitui a riqueza nas sociedades modernas, pois,

em vez da riqueza e da miséria da economia política, existe o homem rico e a necessidade humana rica. O homem rico é ao mesmo tempo aquele que tem necessidade de uma totalidade de manifestações humanas da vida. O homem para quem a sua própria realização existe como uma necessidade interior, como uma carência (MARX, 2006, p.146). 
Neste sentido, quanto maiores e mais complexas forem as necessidades propriamente humanas do indivíduo ou grupo - necessidades espirituais: afetividade, sociabilidade e fruição estética -, mais rico será este indivíduo ou grupo.

Tomando como premissa a relação homem-trabalho, em que estes dois elementos são mutuamente determinantes e determinados no processo de humanização, o trabalho alienado do operário da fábrica (e de qualquer indivíduo pertencente às classes mais pobres, às quais compete a produção de riquezas em uma sociedade caracterizada pela divisão hierárquica do trabalho) promove a consequente alienação deste trabalhador de sua própria humanidade, ou seja, a produção sob o sistema capitalista precisa ser percebida como um processo profundamente desumanizador.

\section{Educação para as artes e sociedade de classes}

O processo de humanização e enriquecimento dos indivíduos e do grupo passa, portanto, pelo desenvolvimento e descoberta de necessidades cada vez mais complexas, principalmente no que diz respeito às necessidades de fruição da obra de arte. Num certo sentido, a educação, e a educação para as artes no que concerne a esta exposição, têm por métier gerar e despertar necessidades junto a indivíduos e grupos, e não apenas suprir necessidades ideais, que muitas vezes nem se encontram nestes contextos.

O processo de (re)humanizar os sentidos do homem, ampliar-lhe a âmbito da reflexão e criar uma sensibilidade genuinamente humana é um desafio histórico posto a cada dia para todos aqueles que trabalham ou se preocupam com a educação e para o artista em particular, pois que este, na sua práxis, ao operar com a matéria, trabalha direta e fundamentalmente com a sensibilidade humana, sem esquecer, no entanto, que a arte, ao ser captada como totalidade, refere-se e capta, por sua vez, a totalidade do homem: o sensível, o cognitivo e o ético (PEIXOTO, 2003, p. 48-49).

A educação em geral, e a educação para a fruição das artes em particular, participa, no entanto, deste processo de humanização, através do contínuo gerar-suprir de necessidades especificamente humanas. Assim, na concepção marxista, a arte assume funções distintas, destacando-se entre elas: sua função ideológica, sua função enquanto geradora de conhecimento e enquanto expressão humana criadora.

$\mathrm{Na}$ sociedade dividida em classes a arte encontra-se vinculada aos interesses das diferentes classes sociais, ou seja, apresenta-se como parte integrante da superestrutura (complexo hegemônico) vinculada aos interesses de classe e expressando a divisão social. Mas, a obra artística deve "ser dotada de certa coerência interna e autonomia relativa, que impedem a sua redução a um mero fenômeno ideológico" (VÁZQUEZ, 1978, p. 26). Embora o artista esteja condicionado ao seu contexto histórico e social, a sua obra não pode ser reduzida a estes fatores.

Segundo Fischer (2002), a arte é "condicionada pelo seu tempo e representa a humanidade em consonância com as ideias e aspirações, as necessidade e as esperanças de uma situação histórica particular" (FISCHER, 2002, p.17). Mas, ao mesmo tempo, "a arte supera essa limitação e [...] cria um momento de humanidade que promete constância no desenvolvimento" (FISCHER, 2002, p.18). A arte apresenta, dessa forma, uma noção de continuidade humana, mesmo em meio à revoluções e rupturas. Portanto, enquanto as ideologias de classe são passageiras e superáveis, a verdadeira arte permanece válida para além de seu contexto histórico e social. 
A arte se torna um elemento de cognoscibilidade no momento em que reflete a realidade histórica e a traduz, ajudando a explicá-la, sempre através do filtro ideológico do artista, mas, assim como a arte não é sinônimo de ideologia, ela também não o é da realidade objetiva.

Diferentemente do que ocorre com a ciência, que procura explicar o mundo, o conhecimento revelado pela arte tem como objeto o homem no mundo, o mundo humano.

O homem é o objeto específico da arte, ainda que nem sempre seja o objeto da representação artística. Os objetos não humanos representados artisticamente não são pura e simplesmente objetos representados, mas aparecem em certa relação com o homem; ou seja, revelando-nos não o que são em si, mas o que são para o homem, isto é, humanizados (VÁZQUEZ, 1978, p. 35).

A arte, portanto, ao contrário das ciências, não revela objetivamente uma parte qualquer do real, mas busca captar e traduzir as relações do homem com a realidade tal como esta se apresenta a ele.

Enquanto forma de conhecimento, a arte estabelece uma relação dialética com o homem, pois na medida em que este cria a obra artística a partir de sua subjetividade, a obra artística, agora objetivação de sua subjetividade, se torna objeto de conhecimento e fruição, recriando o homem neste processo. É nesse sentido que Marx (2006) escreve, em seus Manuscritos econômicos e filosóficos, que

vendo a questão do ponto de vista do subjetivo, verificaremos que o sentido musical do homem é despertado apenas pela música. A música mais bela não tem nenhum sentido para o ouvido não musical, pois não é para ele um objeto, porque o meu objeto só pode ser a manifestação de uma das forças do meu ser. A força do meu ser é uma disposição subjetiva para si, porque o sentido de um objeto para mim só tem sentido para um sentido correspondente e vai precisamente tão longe quanto o meu sentido. [...] Só pelo desenvolvimento objetivo da riqueza do ser humano é que a riqueza dos sentidos humanos subjetivos, que um ouvido musical, um olho sensível à beleza das formas, que numa palavra, os sentidos capazes de prazeres humanos se transformam em sentidos que se manifestam como forças do ser humano e são quer desenvolvidos, quer produzidos. Porque não se trata apenas dos cinco sentidos, mas também dos sentidos ditos espirituais, dos sentidos práticos (vontade, amor, etc.), numa palavra, do sentido humano, do caráter humano dos sentidos que se formam apenas através da existência de um objeto, através da natureza tornada humana. A formação dos cinco sentidos representa o trabalho de toda história do mundo até hoje. $\mathrm{O}$ sentido sujeito às necessidades práticas vulgares não passa de um sentido limitado (MARX, 2006, p.143144).

Ao afirmar que o sentido musical humano só pode ser despertado pela própria música, e, simultaneamente, que a arte musical é produzida apenas pelo ser humano, Marx (2006) torna claro o caráter de mútua determinação na relação homem-trabalho (tanto em relação ao trabalho utilitário quanto à criação estética). Neste sentido, o autor aponta para uma das razões de ser da educação, primordialmente da educação para as artes, ao constatar que estas devem contribuir para a produção dos sentidos humanos para que, escapando às necessidades vulgares, os indivíduos e grupos sociais possam desenvolver 
maiores e mais complexas necessidades espirituais, que contribuam no fortalecimento de sua própria humanização. Mas isso só pode se efetivar na medida em que, no processo educacional, leve-se em conta a necessária reabilitação dos sujeitos submetidos a ele enquanto produtores, através do trabalho, desta mesma humanização, ou seja, através do desenvolvimento de seu potencial criativo.

Portanto, os sentidos, tanto de caráter ideológico quanto cognoscível, da arte devem ser superados pelo sentido mais amplo de atividade humana criadora. A obra de arte é criação humana e deve ser compreendida como uma manifestação do poder criador do homem.

A arte é, portanto, expressão máxima do potencial criador e transformador do homem, mas, como anteriormente apontado, na sociedade capitalista a arte encontra-se frequentemente submetida à lógica industrial, à lógica do trabalho alienado. A arte é arte alienada quando as relações entre artista e público de desfazem, quando a expressão do belo não pode mais ser compreendida pela maioria, especialmente das classes oprimidas, formadas em um sistema educacional de moldes tecnicistas e desumanizadores. Este distanciamento entre artista e público encontra suas origens no processo histórico de segregação e divisão de classes.

Já no Renascimento, a arte se destinava principalmente a dois públicos distintos, sendo eles: as pessoas ligadas direta ou indiretamente à produção e ao consumo, no sentido de aquisição da obra de arte, e os "iniciados", os que efetivamente "apreciavam" as obras. O grande público, por não pertencer ao grupo dos chamados "iniciados", e tampouco dispor de recursos para a aquisição das obras, encontrou-se afastado dos espaços destinados à arte. Hauser (1998) afirma que se originou, neste contexto, um "abismo intransponível entre uma minoria educada e uma maioria carente de educação, abismo que atingia agora proporções nunca vistas e iria ser um fator decisivo em todo o futuro desenvolvimento da arte" (HAUSER, 1998, p. 320-321).

Portanto, na sociedade capitalista, onde tudo se resume à posse, o ter passa a ser o sentido predominante da vida humana, resultando num embrutecimento dessa sociedade, pois essa relação de posse, vinculada ao valor monetário da obra de arte, fecha as portas à fruição estética e humana do objeto artístico. Enquanto grande parte da sociedade, principalmente, nas sociedades divididas em classes, em se tratando das classes oprimidas, não tem acesso às obras artísticas, os poucos privilegiados que podem acessá-la muitas vezes o fazem mais pelo valor de troca ${ }^{5}$ imputado a determinado objeto artístico, ou, ainda, pelo status conferido por este objeto, do que pela fruição da obra em si e pela apreciação das características do universal humano nela objetivado.

Outro aspecto importante é a consideração do papel dos intermediários, aqueles que comercializam as produções dos artistas, que organizam as críticas à obra e que a difundem. Estes personagens não apenas transformam os objetos artísticos em bens capitalizáveis, mas também lançam sua influência sobre os artistas ao definir o que "vende", ou seja, o estilo, gênero ou técnica que deve ser usada na criação da obra pelo artista, baseada em valores das classes dominantes, muitas vezes em detrimento do valor humano e humanizador da experiência estética (PEIXOTO, 2003, p. 27). Nesse sentido, Vázquez (1978) comenta que

na sociedade capitalista, a obra de arte é 'produtiva' quando se destina ao mercado, quando se submete às exigências deste, às flutuações da oferta $\mathrm{e}$ da procura. E, dado que não existe uma medida objetiva que permita determinar o valor desta mercadoria peculiar, o artista conserva-se submetido aos gostos, preferências, ideias e concepções estéticas 
daqueles que influenciam decisivamente o mercado (VÁZQUEZ, 1978, p. 93).

Assim, qualquer que seja a forma da obra relacionar-se com a sociedade capitalista, invariavelmente, tudo se transforma em mercadoria, estando o artista submetido ao capital como profissional liberal, ou seja, submetido a editores, produtores, etc., ou como assalariado da indústria cultural ${ }^{6}$. $\mathrm{O}$ artista, no entanto, só pode criar quando movido por uma necessidade interior de expressão e comunicação, ou seja, quando o faz de forma livre. A hostilidade do capitalismo à arte se faz notar na medida em que o artista, para sobreviver, é levado a submeter-se às leis do mercado, anulando a si mesmo no processo (VÁZQUES, 1978, p. 117).

\section{Arte, mercado e desumanização}

A riqueza do homem dá-se na medida em que este estabelece relações com o mundo, relações novas, amplas, transformadoras. Sob o capitalismo, no entanto, as múltiplas necessidades humanas são negligenciadas em função das necessidades do capital.

Com o desenvolvimento das sociedades capitalistas, com a transformação da força de trabalho em mercadoria, e com a valorização das coisas pelo seu valor de troca, a arte e a sociedade entram em contradição, restando para o artista, de modo geral, duas possibilidades: integrar-se ao sistema, anulando-se e corroborando para o escamoteamento das contradições inerentes ao sistema capitalista; ou permanecer à margem da indústria cultural, sendo sua obra relegada ao segundo plano e, frequentemente, ao esquecimento.

$\mathrm{O}$ sistema de produção capitalista anulou as relações diretas entre produtor e consumidor, lançando todos os seus produtos em um mercado comum.

Em tal mundo, a arte também se tornou uma mercadoria e o artista foi transformado em um produtor de mercadorias. $\mathrm{O}$ patrocinador individual foi invalidado por um mercado livre no qual a avaliação das obras de arte se tornava difícil, precária, e onde tudo dependia de um conglomerado anônimo de consumidores chamado 'público'. A obra de arte foi sendo cada vez mais subordinada às leis da competição (FISCHER, 2002, p.59).

Grande parte da produção artística se dobra ante o modo de produção material e as leis do mercado, e neste sentido o sistema capitalista é hostil ao homem. Não é mais o homem que se serve de sua produção livremente, mas é o sistema produtivo que se serve do homem e o escraviza. Nesse processo, o homem torna-se apenas mais uma "coisa", mais uma engrenagem da máquina produtiva, percorrendo o caminho inverso ao do trabalho livre, pois, enquanto o trabalho e a arte alçaram o homem do ser natural ao ser humano social, a alienação desumaniza o homem, roubando dele a sua liberdade, o produto de seu trabalho e a sua força criadora. Este homem indistinto, desumanizado, perdeu sua capacidade de humanizar o mundo e de transformá-lo, tornando-se manipulável e passível de ser moldado pelas forças do mercado.

Quando a obra de arte entra no mundo do mercado, seu valor intrínseco é substituído pelo seu valor de troca, e neste momento, a arte passa por um processo de padronização para adequar-se a este mercado perdendo sua originalidade e tornando-se arte para as massas.

A arte industrial dos dias atuais alcança grande repercussão entre a população justamente por contar com os meios industriais de distribuição. A produção artística veiculada pela grande mídia é, portanto, em grande parte, exemplo desta pseudo-arte 
compreendida como trabalho banalizado, que não supre as necessidades verdadeiramente humanas, não enriquece o ser do homem, mas mantém-no acorrentado às engrenagens das estruturas da alienação social (VÁZQUEZ, 1978, p. 112).

Embora a tecnologia tenha permitido o acesso e a distribuição das obras de arte ao grande público, em geral não são as verdadeiras obras de arte que são difundidas por esses meios. O discurso construído para justificar a baixa qualidade dos objetos estéticos oferecidos às massas lança sobre as mesmas a culpa por esta qualidade, ao afirmar que os produtores apenas respondem ao que as massas requerem e necessitam, mas, segundo Vázquez (1978), isto é uma mistificação da sociedade, pois

o próprio consumo se encontra dirigido e organizado no sentido de satisfazer as exigências da produção. [...] Nesta relação entre a produção e o consumo, ainda que este desempenhe um papel ativo, a primazia corresponde, em última instância, à produção, já que esta produz não só objetos, mas inclusive o sujeito, o modo de consumi-lo (VÁZQUEZ, 1978, p. 279).

O público, portanto, não é passivo, mas também não é o grande responsável pelo que deve ser produzido para ele, pois mesmo quando o público escolhe o que lhe é agradável ele o faz influenciado, ou mesmo moldado, por uma persuasiva indústria publicitária, e, ainda, sob os efeitos de uma educação que impõe necessidades irreais, assim, "se o público prefere uma arte trivial, vazia, de baixa qualidade estética e humana, esta preferência é um tanto aparente, já que lhe foi induzida, fabricada ou produzida de fora" (VÁZQUEZ, 1978, p. 280-281).

$\mathrm{Na}$ sociedade capitalista, erigida sobre a luta de classes, a lógica da dominação requer que a obra de arte atue enquanto um braço da educação padronizada, no sentido de escamotear as "diferenças sociais existentes na plateia, criando, assim, [...] uma coletividade 'universalmente humana' e não dividida em classes" (FISCHER, 2002, p.14).

A arte para as massas, portanto, é aquela criada por profissionais, e se destina ao grande público heterogêneo, com a intenção de promover a "sujeição feliz" (CANCLINI, 1984, p. 49), promovendo a passividade em relação aos mecanismos de consumo e de reprodução social. Quando a serviço do capitalismo, a arte destina-se à manutenção do homem em uma condição de docilidade e aceitação das condições sociais às quais está submetido, enquanto a educação tecnicista e opressora o capacita para suprir as necessidades do sistema de produção regido pela lógica do mercado.

$\mathrm{O}$ conceito de arte enquanto entretenimento, amplamente divulgado pela mídia, se encontra na raiz do problema, pois, embora arte também possa adquirir características de entretenimento legítimo em muitos casos, ela seguramente não é apenas isso. Adorno e Horkheimer (1982), a respeito desta confluência dos significados de arte e entretenimento, escrevem o seguinte:

A mecanização adquiriu tanto poder sobre o homem em seu tempo de lazer e sobre sua felicidade, determinado integralmente pela fabricação dos produtos de divertimento, que ele apenas pode captar as cópias e as reproduções do próprio processo de trabalho. O pretenso conteúdo é só uma pálida fachada; aquilo que se imprime é a sucessão automática de operações reguladas. Do processo de trabalho na fábrica e no escritório só se pode fugir adequando-se a ele mesmo no ócio. [...] O prazer congela-se no enfado, pois que, para permanecer prazer, não deve exigir esforço algum, daí que deva caminhar estreitamente no âmbito das associações habituais. $\mathrm{O}$ espectador não deve trabalhar com a própria cabeça; o 
produto prescreve qualquer reação. [...] Toda conexão lógica que exija alento intelectual é escrupulosamente evitada (ADORNO; HORKHEINER, 1982, p.175).

A arte legítima necessita promover uma reaproximação com o público. Mas, não é este um caminho de mão única, pois o público precisa também querer aproximar-se da arte, afastando-se da pseudo-arte produzida pela indústria. Trata-se de uma "comunicação que só pode ser alcançada por meio de uma dupla elevação: da qualidade da obra e da sensibilidade artística do público" (VÁZQUEZ, 1978, p. 122).

\section{Conclusão}

Essa sensibilização para com uma obra de arte só pode ser alcançada mediante a disponibilização da obra artística a este público. A sensibilização artística do público deve ser um dos propósitos da educação, na luta pela reconstrução do homem, pela sua libertação e humanização, que só pode acontecer no âmbito do social, do coletivo, pelo trabalho livre e criativo, suportado pela técnica historicamente desenvolvida, e pelo pleno usufruto estético da arte.

\section{Referências}

ADORNO, T. W.; HORKHEIMER, M. A indústria cultura: o iluminismo como mistificação das massas. In. Lima, L. C. Teoria da cultura de massa. $3^{\text {a }}$ ed. Rio de Janeiro: Paz e terra, 1982.

CALLADO, A. Introdução. In FISCHER, E. A necessidade da arte. 9ª . ed. Rio de Janeiro: Guanabara, 1987.

CANCLINI, N. G. A socialização da arte: teoria e prática na América Latina. São Paulo: Editora Cultrix, 1984.

DUROZÓI, G. Dicionário de Filosofia. Campinas, SP: Papirus, 1993.

FISCHER, E. A necessidade da arte. 9ª . ed. Rio de Janeiro: Guanabara, 1987.

HAUSER, A. História social da arte e da literatura. Trad. Álvaro Cabral. São Paulo: Martins Fontes, 1998.

MARX, K. Contribuição à crítica da economia política. $2^{a}$. ed. São Paulo: Expressão Popular, 2008.

Manuscritos econômico-filosóficos. São Paulo: Martin Claret, 2006. . O capital. Rio de Janeiro: LTC, 1982.

MARX, K.; ENGELS, F. O Manifesto Comunista. Rocket Edition, 1999. Disponível em Www.jahr.org

MÉSZÁROS, I. Para além do capital. Trad. Paulo Cezar Castanheira. São Paulo:

Boitempo, 2002.

OSTROWER, F. Criatividade e processos de criação. Petrópolis: Vozes, 1987.

PEIXOTO, M. I. H. Arte e grande público: a distância a ser extinta. Campinas, SP:

Autores Associados, 2003. 
REALE, G. História da Filosofia: do romantismo ao empiriocriticismo. São Paulo: Paulus, 2005.

VÁZQUEZ, A. S. As ideias estéticas de Marx. Trad. Carlos Nelson Coutinho. 2a . ed. Rio de Janeiro: Paz e Terra, 1978.

${ }^{1}$ Mestre em Educação (UEPG) e Licenciada em Música (UFPR), integra o quadro de professores do Departamento de Artes da Universidade Estadual de Ponta Grossa. E-mail: carlaroggenkamp@ yahoo.com.br

${ }^{2}$ Mestrado em Educação (UEPG) Doutorado em Engenharia de Produção - Midia e conhecimento (UFSC) Professora orientadora do mestrado/doutorado no Programa de Pós-Grauduação da UEPG, Coordenadora do Grupo de Estudos e Pesquisas em Educação Arte e Comunicação. Pesquisadora Sênior da Fundação Araucária. E-mail: mjsubtil@gmail.com

${ }^{3}$ Conceito desenvolvido inicialmente por Marx, indicativo da exploração do operário, pois, para gerar lucro ao proprietário dos meios de produção, faz-se necessário que o número de horas trabalho produzam mais valor de troca do que o operário recuperará sob a forma de salário, produzindo a mais-valia, ou seja, trabalho não-pago (DUROZÓI, 1993, p. 302-303).

${ }^{4}$ A alienação do trabalhador consiste em que "o trabalho permanece exterior ao operário, isto é, não pertence ao seu ser, e o operário, portanto, não se afirma em seu trabalho, e sim se nega, não se sente satisfeito, mas infeliz; não desenvolve nenhuma livre energia física e espiritual, mas modifica seu corpo e arruína seu espírito [...], seu trabalho não é voluntário, mas forçado, é trabalho constritivo” (REALE, 2005, p. 191).

${ }^{5}$ Segundo Marx (1982), o valo de uso de um objeto é determinado na medida em que este "satisfaz para seus proprietários uma necessidade humana qualquer. [...] É a utilidade de uma coisa que lhe dá um valor de uso" (MARX, 1982, p.24). Em contrapartida, o valor de troca deste mesmo objeto é determinado pela "quantidade de trabalho socialmente necessário" (MARX, 1982, p.26) à sua produção, ou seja, trabalho humano acumulado, pois, "quanto maior a força produtiva de trabalho e menor o tempo de trabalho necessário para a produção de um artigo, tanto menor a quantidade de trabalho que aí se encontra cristalizada e consequentemente menor o seu valor. Inversamente: quanto menor a força produtiva de trabalho e mais longo o tempo de trabalho necessário à produção de um artigo, tanto maior o seu valor" (MARX, 1982, p.27).

${ }^{6}$ Por indústria cultural entendem-se aqui os meios de produção e distribuição massiva de produtos voltados ao entretenimento e ao apaziguamento da população. O termo adquire conotação negativa para os autores da Teoria Crítica por ser considerado um escamoteamento das injustiças sociais às quais a maioria da população encontra-se submetida. Segundo Adorno e Horkheimer (1982), a indústria cultural concentra-se na técnica de modo a que, em diferentes contextos locais, "necessidades iguais sejam satisfeitas com produtos estandardizados" (ADORNO; HORKHEIMER, 1982, p.160). Os diferentes produtos então distribuídos pela indústria cultural são programados para serem consumidos em "estado de distração. Mas cada um destes é um modelo do gigantesco mecanismo econômico que desde o início mantém tudo sob pressão tanto no trabalho, quanto no lazer que lhe é semelhante" (ADORNO; HORKHEIMER, 1982, p.165). Estes autores afirmam ainda que o lazer se torna semelhante ao trabalho alienado (portanto, lazer alienado) na medida em que os mesmos mecanismos de controle se estabelecem tanto no primeiro como no segundo. O lazer é préfabricado e industrializado de modo a manter o indivíduo em uma condição de consumo passivo. Os próprios artistas acabam por sucumbir à lógica da indústria cultural ao serem tolhidos de sua autonomia, e, quando isso acontece, a pseudo-arte produzida tem por função ocultar "a contradição, em vez de acolhê-la, na consciência da própria criação” (ADORNO; HORKHEIMER, 1982, p.194).

Recebido: junho-15 Aprovado: outubro-15 